Como citar este artigo

Nóbrega MPSS. [Desafio vencido: a Revista Paulista de Enfermagem - REPEn está de volta]. Rev Paul Enferm [Internet]. 2018;29(1-2-3):1-2.

\section{Desafio vencido: a Revista Paulista de Enfermagem - REPEn - está de volta}

\author{
Maria do Perpétuo S. S. Nóbrega ${ }^{\mathrm{I}}$
}

\begin{abstract}
Editora Chefe da Revista Paulista de Enfermagem- Repen/ Diretora do Centro de Estudos e Pesquisa em Enfermagem da Associação Brasileira de Enfermagem Seção São Paulo / Docente da Escola de Enfermagem da Universidade de São Paulo
\end{abstract}

A divulgação científica de qualidade é essencial para que profissionais adquiram conhecimento sobre a enfermagem e entendam melhor o quanto ela está presente em nosso entorno. Para ampliar este conhecimento, publicações de qualidade são essenciais, pois auxiliam a criar uma cultura científica.

É nesse entendimento que ocorre a revitalização da Revista Paulista de Enfermagem (REPEn), da Associação Brasileira de Enfermagem, Seção São Paulo (ABEn-SP). Ela renasce graças ao esforço e entusiasmo da Diretoria do Centro de Estudos e Pesquisa em Enfermagem (CEPEn) e da Diretoria da Associação Brasileira de Enfermagem, Seção São Paulo (Gestão 2017-2019).

Criada em 21 de fevereiro de 1981, a REPEn, periódico oficial da ABEn-SP, teve como preocupação, ao longo de sua trajetória, a publicação de estudos que mostrassem a atuação da Enfermagem em torno de várias pautas, contribuindo para o avanço da profissão.

Ao longo de seus 37 anos, a REPEn deixou de ser publicada por oito anos (última publicação foi em 2009, v.28), retornando agora com o objetivo de continuar como um importante veículo de comunicação científica para o Estado de São Paulo, para o Brasil e para o mundo. Tem por finalidade divulgar a produção científica de interesse da Enfermagem, incluindo a que expresse o projeto político da ABEn-SP. Seu público-alvo são estudantes e profissionais de Enfermagem e de demais áreas da Saúde.

O processo de revitalização foi iniciado no segundo semestre de 2017. Inicialmente, foram resgatados todos os artigos arquivados e aprovados pelos pareceristas da época. Posteriormente, realizado contato com os autores para verificar a publicação prévia do artigo, e em negativa, o interesse em publicá-lo. Após essa fase e com o consentimento dos autores, foi composto o v. $29 n^{\circ}$. 1, 2, 3, 2018; Janeiro/Dezembro, aqui presente.

As alterações conduzidas na política editorial da REPEn até o momento dizem respeito a: publicação exclusivamente na versão eletrônica, mudança no lay-out, novo conselho editorial e pareceristas ad hoc, processo de preparo, submissão, avaliação e editoração dos manuscritos. Informes sobre esses aspectos estão disponíveis no site da REPEn (www. repen.com.br). A REPEn está indexada na base BDENF e no LILACS, e terá periocidade quadrimestral. 
Os 14 artigos que compõem o volume 29 abordam: a atuação de enfermeiros de unidades pediátricas hospitalares na educação em saúde; a dramatização como estratégia facilitadora no processo ensino aprendizagem dos estudantes de enfermagem; a análise crítica da formação de auxiliares/técnicas de enfermagem; a autonomia profissional da enfermeira obstétrica; os desafios contemporâneos da prática docente; a formação dos profissionais para o trabalho com famílias; o gerenciamento de riscos no contexto hospitalar; padrão de registro de enfermagem e requisitos legais; a participação paterna no pré-natal; remoções em neonatos; representação social acerca dos usuários de álcool/drogas; acidentes com material biológico; vivência materna e sífilis, e questões éticas no exercício da enfermagem.

O processo de revitalização da REPEn tem implicado em trabalho árduo com vistas a manter esse conceituado periódico atrativo e sustentável. Esforços serão conduzidos para que a classificação da REPEn alcance o patamar desejado. A REPEn espera receber seu manuscrito para compor os próximos volumes.

Toda ajuda recebida foi bem acolhida no propósito de revitalizar a REPEn. Agradecimentos são importantes e se expressam no apoio recebido da Diretoria da Associação Brasileira de Enfermagem São Paulo, da Diretoria da Associação Brasileira de Enfermagem Nacional, em particular da Diretoria do Centro de Publicações e Comunicação Social, e da Diretora do Centro de Estudo e Pesquisas em Enfermagem da ABEn Nacional.

Considerando que há excelentes periódicos de publicação de Enfermagem no país, projeta-se que a REPEn pode fazer a diferença, atraindo e ofertando conteúdos de qualidade para a comunidade.

Encerra-se esse editorial com as palavras de Jane Robinson que traduzem o momento importante para a REPEn: "Uma comunidade global de enfermeiras dedicada a melhorar os indicadores de saúde e os padrões de provimento de cuidados deveria usar todos os meios para se comunicar livremente" ${ }^{\prime \prime}$.

Bem-vinda REPEn, a Enfermagem te espera!

\section{REFERÊNCIA}

1. Robinson J. Publique e seja criticado. Rev Esc Enferm USP [Internet]. 2006 [cited 2018 Nov 06];40(1): 7-8. Available from: http://dx.doi.org/10.1590/S0080-62342006000100001 